\title{
Are You Still Watching?
}

\section{ILAKKIAH CHANDRAN}

Department of Psychology, University of Toronto Scarborough, Canada

As of January 2020, there are over 167 million Netflix subscribers worldwide, many of whom enjoy shows like The Office, movies like Roma, or documentaries like The Keepers (USA Today, 2020). Recently, Netflix and other streaming services like Disney+ and Amazon Prime have become extremely popular means of entertainment. As a consistent Netflix user, I do enjoy coming home after a long day of classes to treat myself to my favourite shows. Still, sometimes one episode becomes two, two becomes three, and I eventually find myself confronted by the question that snaps me back into reality, "Are you still watching Grey's Anatomy?" Binge-watching is a streaming pattern that individuals often practice with the intention of relaxation; however, it can also lead to feelings of guilt and procrastination (Granow et al., 2018). Many studies over the last decade have looked at both the positive and negative effects this behaviour has on the well-being of individuals, such as increased feelings of autonomy and the tendency for a sedentary lifestyle (Granow et al., 2018; Feijter et al., 2016). As evidenced by the research on self-control, consistent bingewatching leads to daily challenges and long-term consequences of which individuals are often unaware (Feijter et al., 2016; Ahmed, 2017). These consequences include the persistent impact on binge-watchers' mental and physical health, socialization, and their ability to reach goals. Taking this into consideration, streaming services should provide the option for users to predetermine screen time limits to reduce these effects.

Since self-identifying binge-watchers stream for $3+$ hours without taking a break, it follows that this behaviour may impede successful completion of their short-term goals (Karmakar et al., 2015). Many individuals who binge-watch after work or school tend to have trouble socializing and completing simple household chores they had initially planned to complete (Walton-Pattison et al., 2018). Consequently, the initial excitement binge-watchers feel when enjoying a show doesn't last. As a result of incomplete tasks and goals, they face contradicting feelings (i.e., guilt). This makes the overall experience unpleasant (Granow et al., 2018; Riddle et al., 2018). Moreover, a study by Vaterlaus et al. (2019) found that college students often miss out on plans like dinners and other social events to squeeze in those last few episodes of their favourite show. Although 
individuals are initially satisfied, goalconflicts such as the fear of missing out and the potential guilt of being a lousy friend may creep up on them later on (Jacobs, 2017).

As people spend more time watching TV, they are more likely to postpone shortterm tasks for the enjoyment of streaming (Granow et al., 2018). This consequence significantly reduces productivity and goal attainment as binge-watchers choose the more immediate reward of streaming. The consistent challenges faced due to bingewatching behaviours create a significant barrier; many binge-watchers are unaware that this may be preventing them from achieving their full potential. In fact, binge-watchers who experience goal conflict as a result of binge-watching also experience reduced goal setting (WaltonPattinson et al., 2018). Once individuals stop goal-setting, their productivity, willpower and self-control significantly decrease, which further creates consequences for our socialization, career, financial sustainability, and overall fulfilment (Walton-Pattinson et al., 2018).

Aside from the impacts binge-watching has on personal goals, it has significant health-related consequences. Research suggests that media plays a vital role in how individuals regulate their emotions and motivations (Rubenking \& Bracken, 2018). Given this information, bingewatching has the potential to increase one's dependency on TV to regulate, control, and express their emotions, leading to increased feelings of loneliness and isolation (Jacobs, 2017). Moreover, streaming for so long in one sitting is correlated with a sedentary lifestyle (Walton-Pattison et al., 2018). As individuals engage in binge-watching behaviours for extended periods of time, they are less able to inhibit accompanying behaviours, such as snacking, and are less likely to initiate exercise (Walton-Pattison et al., 2016). Walton-Pattison et al. (2018) indicate that, ultimately, intention and goal outcomes are often conflicted by increased binge-watching behaviours. The same article also suggests that the lack of self-control associated with bingewatching is similar to that of other binging behaviours (i.e., substance abuse) (WaltonPattison et al., 2018). These behaviours affect their ability to regulate daily activities, such as reducing snacking, regulating sleep, and initiating exercise (Walton-Pattison et al., 2018). Considering that health should be a priority for most individuals, this behaviour significantly reduces binge-watchers' ability to regulate behaviours necessary to maintain their physical and mental health (Jacobs et al., 2017; Vaterlaus et al., 2019, Panda \& Pandey, 2017).

The implementation of a time limit option would establish restrictions before bingewatchers become attached to their streaming, helping to prevent bingewatching and its inevitable consequences. This feature would notify the user when 
they reach their limit. To continue watching, users would have to override the limit with a password. This feature would reduce the existing automaticity in these streaming services by allowing users to pause and remember tasks outside of streaming. As research suggests, providing "charismatic barriers" can be used to introduce pauses that combat bingewatching behaviour (Skibins et al., 2019). Research also indicates that impulsivity plays a role in binge-watching behaviours, as individuals who hadn't initially intended to stream for hours may do so based on impulse, indicating that this behaviour is modifiable (Walton-Pattison et al., 2016; Vens \& Farrar, 2021). Therefore, this time-limit option will reduce the "modifiable option," providing opportunities to break the binge-watching cycle. Lastly, taking a quick break from watching may enable users to initiate healthy behaviours and reduce mindless snacking.

Although this feature can reduce the negative consequences associated with binge-watching, it is not a complete solution (Skibins et al., 2019). Individuals can still override this feature, which will result in the same consequences as before. Furthermore, if individuals are attempting to relax, the positive effects, such as the feeling of autonomy and pleasure, may be reduced if there are predetermined restrictions, resulting in guilt and unpleasantness, which may lead to users finding the overall streaming experience unpleasant (Panda \& Pandey, 2017; Granow et al., 2018). However, given that this feature is optional (i.e., can be turned on and off), if implemented correctly and used regularly, it has the potential to reduce goal-conflicts and the negative implications associated with bingewatching.

Although binge-watching is an activity often undertaken for pleasure, it can lead to goal-conflict, reduced goal setting, and long-term implications on well-being. Implementing a tool that allows users to restrict themselves before binge-watching would likely promote self-control and reduce short- and long-term consequences of binge-watching. 


\section{References}

Ahmed, A. A. A. M. (2017). New era of TV-watching behavior: Binge watching and its psychological effects. Media Watch, 8(2), 192-207. http://doi.org/10.15655/mw/2017/v8i2/49006

Feijter, D., Khan, V. J., \& van Gisbergen, M. (2016, June). Confessions of a'guilty'couch potato understanding and using context to optimize binge-watching behavior. Proceedings of the ACM International conference on interactive experiences for TV and online video (pp. 59-67). Association for Computing Machinery. http://doi.org/10.1145/2932206.2932216

Granow, V. C., Reinecke, L., \& Ziegele, M. (2018). Binge-watching and psychological wellbeing: Media use between lack of control and perceived autonomy. Communication Research Reports, 35(5), 392-401. http://doi.org/10.1080/08824096.2018.1525347

Jacobs, R. A. (2017). Is There a Relationship Between Binge Watching and Depressive Symptoms? (Doctoral dissertation, Immaculata University).

Karmakar, M. (2015, November). Viewing patterns and addiction to television among adults who self-identify as binge-watchers. 2015 APHA Annual Meeting \& Expo. APHA.

Panda, S., \& Pandey, S. C. (2017). Binge watching and college students: Motivations and outcomes. Young Consumers, 18(4), 425-438. https://doi.org/10.1108/YC-07-2017-00707

Riddle, K., Peebles, A., Davis, C., Xu, F., \& Schroeder, E. (2018). The addictive potential of television binge watching: Comparing intentional and unintentional binges. Psychology of Popular Media Culture, 7(4), 589. https://doi.org/10.1037/ppm0000167

Rubenking, B., \& Bracken, C. C. (2018). Binge-watching: A suspenseful, emotional, habit. Communication Research Reports, 35(5), 381-391. http://doi.org/10.1080/08824096.2018.1525346

Skibins, J. C., \& Sharp, R. L. (2019). Binge watching bears: Efficacy of real vs. virtual flagship exposure. Journal of Ecotourism, 18(2), 152-164. http://doi.org/10.1080/14724049.2018.1553977

USA Today. (2020, January 22). Netflix adds 8.8 million new subscribers, 'The Witcher' tracks as most-viewed new series. https://www.usatoday.com/story/tech/2020/01/21/netflix-adds-8-8million-new-subscribers-now-has-100-m-outsideus/4490819002/ 
Vaterlaus, J. M., Spruance, L. A., Frantz, K., \& Kruger, J. S. (2019). College student television binge watching: Conceptualization, gratifications, and perceived consequences. The Social Science Journal, 56(4), 470-479. https://doi.org/10.1016/j.soscij.2018.10.004

Viens, A., \& Farrar, K. M. (2021). Conceptualizing and Measuring Binge Watching. Communication Studies. https://doi.org/10.1080/10510974.2021.1876748

Walton-Pattison, E., Dombrowski, S. U., \& Presseau, J. (2018). 'Just one more episode': Frequency and theoretical correlates of television binge watching. Journal of health psychology, 23(1), 17-24. https://doi.org/10.1177/1359105316643379 